DOI 10.37882/2500-3682.2020.06.08

\title{
К ВОПРОСУ О ФИЛОСОФСКОМ ОСМЫСЛЕНИИ РОЛИ КУЛЬТУРНОЙ ПАМЯТИ В ОБЩЕСТВЕННОМ РАЗВИТИИ
}

\section{ON PHILOSOPHICAL THINKING ON THE ROLE OF CULTURAL MEMORY IN SOCIAL DEVELOPMENT}

\author{
V. Lunev \\ R. Musat \\ T. Luneva \\ N. Knyazev \\ O. Neskryabina \\ D. Rakhinsky
}

Summary: The article discusses the mechanisms of influence of cultural memory on the development of society. The concepts of «collective memory», «cultural memory», "communicative memory», "cultural trauma» have been analyzed. It has been shown that cultural memory can determine the vector of social development. We see the mechanism as a dialogue between a society that represents cultural memory and a history that represents an expert community. As a result of this dialogue, involving a large number of alternative voices and opinions, memory gaps can be filled, myths lose their relevance, cultural trauma are integrated, and society forms has a common past and a common future.

Keywords: collective memory, communicative memory, trauma of cultural memory, social reflection, social development.

Лунев Владимир Викторович

К.с.н., дочент, ФГАОУ ВО «Сибирский федеральный университет» (2. Красноярск) vladimirL1@yandex.ru

Mусат Раиса Павловна

Д.фр.н., дочент, ФГАОУ ВО «Сибирский феедеральный университет» (2. Красноярск)

lozraisa@yandex.ru

Лунева Татьяна Анатольевна

К.т.н., дочент, ФГБОУ ВО «Сибирский государственный университет науки и технологий имени академика М.Ф.

Решетнева» (2. Красноярск)

luneva@sibsau.ru

Князев Николай Алексеевич

Д.ф.н., профрессор, ФГБОУВО «СИбирский государственный университет науки и технологий имени академика М.Ф.

Решетнева» (2. Красноярск)

knyazev@sibsau.ru

Нескрябина Ольга Федоровна

Д.ф.н., профрессор, ФГБОУВО «Красноярский

государственный медицинский университет имени профессора В.Ф. Войно-Ясенецкого» (г. Красноярск)

nescr@mail.ru

Рахинский Дмитрий Владимирович

Д.ф.н., дочент, ФГБОУ ВО «Красноярский государственный аграрный университет» (2. Красноярск) siridar@mail.ru

Аннотация: В статье рассмотрены механизмы влияния культурной памяти на развитие общества. Проанализированы понятия «коллективная память», «культурная память», «коммуникативная память», «культурная травма». Показано, что культурная память может определять вектор общественного развития. Механизм видится нами как диалог между обществом, представляющим культурную память и историей, представляющей экспертное сообщество. В результате такого диалога с привлечением большого числа альтернативных голосов и мнений пробелы в памяти могут быть заполнены, мифы теряют свою необходимость, культурные травмы интегрируются, а у общества формируется общее прошлое и общее будущее.

Ключевые слова: коллективная память, коммуникативная память, травма культурной памяти, социальная рефлексия, общественное развитие.

альных групп [20, с. 138]. Именно общество и социальные группы определяют рамки памяти - каждый раз решая, что сохранять, а что придавать забвению.

Идеи М. Хальбвакса получили развитие в работах немецких историков и культурологов Я. Ассмана и А. Ассман. В социальной памяти они предложили выделять несколько слоев, существующих на разных уровнях социального сознания, но при этом влияющие друг на дру- 
га. Так, Я. Ассман в социальной памяти предлагает различать две опции - коммуникативную и культурную память. Коммуникативная память - это воспоминания, связанные с недавним прошлым. Это память примерно трех поколений, которая со временем исчезает и уступает место памяти следующих поколений [6, с. 52-53]. А. Ассман, чья работа вышла позже, предложила называть этот тип памяти - социальной памятью поколений [7, с. 33].

Примерами коммуникативной памяти могут служить исследования отечественных социологов, которые показывают, что даже в рамках двух-трех поколений исторические и культурные события теряют свою важность и меняют вектор оценки. Так, например, исследования Л.И. Миклиной культурной памяти среди молодежи показывают, что некоторые исторические события, имевшие большую значимость для общества еще несколько десятилетий назад (Революция 1917 года, Гражданская война), в глазах современного молодого поколения либо вообще не имеют значение, либо оцениваются в целом отрицательно («террор», «ужас», «кошмар» и т.д.) [15, с. 139].

Исследования Т.А. Андрияновой, проведенные среди студентов также подтверждают, что даже в рамках одного поколения (2012 г., 2015 г.) со временем меняются представления о культурных и исторических ценностях, важности тех или иных исторических событий. Меняется и фокус памяти. Для представителей более взрослого поколения может вызвать удивление тот факт, что почти треть опрошенных студентов считает, что первый космический спутник на орбиту земли вывели США, а значительная часть студентов гуманитарных специальностей не знает, где расположен музей «Эрмитаж» [4, с. 18].

Еще более информативными являются результаты многолетних исследований коллективной памяти, проведенные А.Н. Покидой и Н.В. Забуновской. Они показывают, что всего за пятнадцать лет (с 2001 по 2015 год) в стране потеряли историческую ценность такие события, как «Эпоха Петра |», «Победа в Отечественной войне 1812 г.», «Отмена крепостного права», «Освобождение от татаро-монгольского ига», «Революция 1917 года», «Русскояпонская война» и др. [17, с. 103-104].

В отличие от оперативной памяти поколений культурная память носит долгосрочный характер, она на долгое время сохраняет культурные артефакты, символы, смыслы и знаки. Прошлое представлено в ней символическими фигурами в виде мифов, традиций и артефактов [6, с. 5456]. Описывая символический смысл культурной памяти, Я. Ассман приводит пример холокоста. Холокост - это исторический факт. Однако для государства Израиль холокост стал гораздо большим явлением, - он стал обосновывающей историей, мифом, из которого государство черпает свою легитимность и строит свою идентичность [6, с. 81].
Культурная память привязана уже не к поколениям, а к большим социальным группам. В этом смысле можно выделить культурную память мировой цивилизации, отдельных стран и народов. Ее носителями помимо больших социальных групп и социальных институтов выступают также писатели, политики, религиозные деятели, ученые - и все те, кто может читать культурные коды и участвовать в сохранении и передачи культурного наследия $[6$, с. 56].

Как верно отмечает А. Завадский, для сохранения культурной памяти и передачи ее следующим поколениям важно, чтобы общество сохраняло свои воспоминания посредством материальных носителей (памятников, музеев, библиотек, книг, фильмов и т.д.) [9, с. 502]. При этом, как показывает П. Нора, отбор содержания памяти для его сохранения и последующей передачи во многом зависит от настоящего, политической конъюнктуры и понимания в обществе будущего [16].

Также открытым остается вопрос о функциях культурной памяти, ее влияние на современность и будущее. Анализируя работы М. Хальбвакса, Я. Ассмана, А. Ассман, П. Нора, К. Леви-Стросса, Ю.М. Лотмана, на наш взгляд, можно выделить четыре основные функции культурной памяти: накопительную функцию, функцию сохранения национальной идентичности, функцию обеспечения социального развития и функцию обеспечения этической преемственности. В данной работе нами будет рассмотрена функция обеспечения социального развития.

Впервые на роль памяти в развитии сложных систем обратили внимание представители синергетики. Так, Л.Г. Мельник, анализируя открытые системы, отмечает, что обязательным условием их развития является наличие у системы памяти [14, с. 215]. Память нужна для того, чтобы система «знала» и помнила возможные способы самоорганизации и направления развития.

По мнению Е.Н. Князевой и С.П. Курдюмова, память системы служит своеобразным механизмом возвращения системы к ее целям, корректировки движения и самоорганизации. В социальных системах происходит сравнение того, что было с тем, что есть и это становится источником для новых форм и способов движения вперед $[10$, c. 95-100].

Таким образом, память системы как бы уже содержит в себе возможные варианты ее развития. Необходимо отметить, что сам по себе механизм воспроизводства памяти сложных социальных систем еще слабо изучен и требует дальнейших исследований. Вместе с тем, очевидно, что он является одним из важнейших условий протекания сложных синергетических процессов.

В связи с этим перспективным представляется под- 
ход А.П. Руденко, который предлагает различать два типа самоорганизации - когерентную (или синергетическую) и континуальную (или синкретическую). Он выделяет различия в морфологических особенностях, составе, структуре и свойствах неравновесных объектов двух типов самоорганизации. Механизм когерентной самоорганизации связан с кооперативным взаимодействием множества однородных компонентов, приводящим к синхронизации внутренних процессов и их когерентному поведению. Напротив, синкретическая самоорганизация предполагает взаимодействие разнородных компонентов. Такой механизм можно назвать синкретическим (от греческого «Synkretismos»слитное, нерасчлененное соединение разнородного).

Одним из наиболее существенных различий данных типов самоорганизации является неспособность первого типа и способность второго типа к прогрессивной эволюции с естественным отбором новых качеств. В первом случае мы сталкиваемся с «пассивным», а во втором случае - «активным» способом упорядочения хаоса. То есть второй тип самоорганизации возникает тогда, когда элементы системы выступают не пассивными получателями влияния внешней среды, а активными творцами нового. Эта идея открывает новые перспективы для исследования процессов самоорганизации разной природы.

Наряду с этим А.П. Руденко также считает, что самоорганизация может быть «созидательной», направленной на развитие, потребляющей внешнюю энергию и «разрушительной», направленной на деградацию системы. Примером первого случая может быть прогрессивное развитие СССР после Октябрьской революции, примером второго - развал и распад СССР [19].

Согласно Я. Ассману, коллективная память также не только воспроизводит прошлое, но и конструирует будущее [6, с. 43]. Можно сказать, что в культурную память заложен определенный механизм социальной рефлексии - оценке своего прошлого, его определенной переработке и проектирования с этим учетом будущего. Однако, как отмечает Т. Адорно, вопрос о том, как происходит эта «проработка прошлого» посредством социальной рефлексии во многом остается открытым [1].

Мы согласны с тем, что культурная память содержит в себе двойственные установки - как возможность для социального развития, так и возможность для повторения ошибок истории. Все зависит от того, как будет построен этот диалог с прошлым [18, с. 84]. Как уже отмечалось, прошлое не вспоминается «ради него самого». Воспроизводство прошлого в культурной памяти всегда выступает либо движущей силой развития, либо заморозкой настоящего или обоснованием преемственности $[6$, с. 80].
Что обуславливает результат встречи настоящего и будущего? Я. Ассман и К. Леви-Строс предлагают деление обществ на «холодные» и «горячие» В зависимости от того, насколько в обществах развита система социальной рефлексии или система замораживания своей истории. Общества, способные к социальной рефлексии («горячие общества»), могут извлекать уроки из истории и двигаться вперед. Общества, склонные к сильной мифологизации прошлого («холодные общества»), замораживают социальные изменения. Немалую роль в этом играет «система охлаждения памяти» - социальные институты, через которые холодные культуры замораживают исторические изменения. Например, это могут быть военное сословие, церковь, институт власти, средства массовой информации [6, с. 73-83; 11].

Нам кажется, что процесс встречи прошлого и настоящего можно представить в двух аспектах, как рефлексию прошлого со стороны новых поколений и как движение в еще «незанятое» прошлым будущее. Таким образом, общество всегда старается сформировать будущее на основе прошлого опыта, встраивая его в определенные рамки памяти. Осложняет этот процесс явление, получившее название «травматизация памяти» или «травма культурной памяти».

Как отмечают исследователи, коллективная память может содержать травмирующие события, оценка которых может существенно отличаться от исторической. Проявляются они обычно в коммуникативном слое памяти, который несет в себе наибольшую эмоциональную нагрузку. Культурная травма включает в себя комплекс психологических переживаний прошлого опыта, связанных с идентичностью группы [5, с. 80]. Она возникает, когда члены сообщества вынуждены переживать негативные события, оставившие след в групповом сознании и способное изменить или повлиять на их идентичность $[3$, c. 6].

X. Вельцер приводит пример, показывающий, как действует на воспоминания культурная травма. Многие жители Дрездена, пережившие налет авиации союзников в феврале 1945 года, после войны были убеждены, что самолеты после налета охотились на людей, летая на бреющем полете. Историк Х. Шнатц доказал, что воспоминания дрезденцев являются мифом. Так как из-за высокой температуры воздуха, связанной с пожаром, самолеты союзников не могли бы летать так низко над городом. Этот вывод подтверждал и анализ бортжурналов летчиков. Однако данный доклад вызвал в обществе скандал, а присутствующие на докладе свидетели событий рассказывали новые подробности налета, обвиняя историков во лжи [8].

Часто спасительным выходом для общества, пережившего культурную травму, становится забвение и/или мифо- 
логизация травмирующих воспоминаний. Так, например, в СССР не принято было говорить о сталинских репрессиях. Эта тема долгое время предавалась забвению. Очевидно, что и забвение и мифологизация травмы играют роль «терапевтического» буфера, защищающего людей от неприятных переживаний. Как пишет А. Ассман, иногда требуются десятилетия, чтобы о травме вообще стало возможным заговорить [7, с. 61].

Х. Вельцер считает, что проработка культурных травм во многом зависит от того, каким образом воспоминания используются в настоящем, как они будут трактоваться. Возможно, когда травма очень сильная, то забвение на какое-то время действительно является необходимым условием ее проживания в дальнейшем. При этом важным становится форма и язык, на котором будет происходить репрезентация травмирующего опыта [8].

Непрожитые культурные травмы мешают объективной оценке исторического опыта, мифологизируя и искажая его. Поэтому одна из задач, стоящих перед обществом, становится безопасное проживание травмы, способное восстановить и перенастроить национальную идентичность. Одним из способов проживания травмы, отмечает Р. Айерман, может быть широкий общественный диалог с привлечением большого числа альтернативных голосов и мнений. Травматический опыт требует заново интерпретировать прошлое, чтобы пришло примирение с настоящим и будущим. В процессе диалога происходит соединение личных историй и коллективных представлений, что в итоге создает единый нарратив [2, с. 42-54]. Такой диалог часто является единственной формой социальной рефлексии при наличии большого количества культурных травм в прошлом опыте.

Движение в «незанятое» будущее предполагает, что конструирование будущего опирается на нежелание общества повторять исторические ошибки прошлого. Удерживаемые в памяти как положительные, так и отрицательные оценки являются своего рода ориентиром, метками, обеспечивающими поступательное развитие, а не хождение по кругу. Для этого также необходим диалог истории и культурной памяти. Это связано с тем, что память позволяет через прошлое актуализировать важнейшие аспекты настоящего - выделяя то, что действительно важно для общества сегодня. Историческая наука не различает важное и неважное, она с одинаковой беспристрастностью относится к любым периодам прошлого. Но при этом только история может вынести объективную оценку происходившему и отделить мифы от реальности. Однако мы не должны забывать, что ускорение социального-экономического развития современ- ного общества снижает значимость опыта предыдущих поколений, тем самым формируя риски для совершения похожих ошибок [21, с. 628]. Данный процесс порождает следующее противоречие: отсутствие связей между поколениями это, с одной стороны - трагедия, с другой жесткая объективная необходимость [13, с. 26].

Общий механизм обеспечения социального развития видится нами следующим образом: общество посредством культурной памяти выбирает наиболее актуальные темы для социальной рефлексии, эти темы обычно связаны с забвением, неопределенностью трактовок или культурной травмой. Очевидно, что культурная память выделяет те пласты исторического опыта, которые до сих пор не переработаны обществом. Но именно от их проработки зависит движение вперед. Затем происходит диалог между обществом, представляющим культурную память и историей, представляющей экспертное сообщество. В результате пробелы в памяти могут быть заполнены, мифы теряют свою необходимость, а травмы интегрируются, у общества формируется общее прошлое и общее будущее. Безусловно, как показывает практика, это долгий процесс, который может занимать много времени и зависит от степени готовности к нему общества и отдельных социальных групп [2, с. 42-54.]. Но таким образом освобождается дорога для будущего, и общество получает пространство для развития. Говоря языком синергетики, система стремится в «незанятое» пространство. Но и здесь общество не смогло полностью обезопасить себя, как ранее отмечалось: «... социальные параметры, на уровне личности вырабатывают стратегии поведения, в основе которых лежит ориентация на ее приспособление и выживание в той социокультурной среде, в которой она оказалась. Как следствие, поведение личности становится более рациональным, расчетливым, направленным на индивидуальные, а не коллективные выгоды» [12].

Если диалога между коллективной памятью и историей не происходит, то можно предположить, что есть опасность, что через забвение или мифологизацию памяти общество попытается «прожить заново незавершенную историю» - реконструировать события прошлого в настоящем. В этом случае существует вероятность повторения ошибок истории. История уже знает такие примеры, все они закончились новыми социальными катастрофами.

Таким образом, культурная память связывает прошлое, настоящее и будущее. Она способна определять вектор общественного развития. Выбор направления будет зависеть от способности общества к внутреннему диалогу и социальной рефлексии. 


\section{ЛИТЕРАТУРА}

1. Адорно Т. Что значит проработка прошлого // Неприкосновенный запас, 2005. - № 4. - [Электронный ресурс] - Режим доступа:https://magazines.gorky. media/nz/2005/2/chto-znachit-prorabotka-proshlogo.html.

2. Айерман Р. Культурная травма и коллективная память // Новое литературной обозрение, 2016. - № 5. - С. $42-54$.

3. Александер Д., Куракин Д.Ю. Культурная травма и коллективная идентичность // Социологический журнал, 2012. - № 3. - С. 5-40.

4. Андриянова Т.В. Историческая память студенческой молодежи региона и проблема ее фальсификации // Историческая и социально-образовательная мысль, 2018. - Т. 10. - № 5/2. - С. 13-20.

5. Аникин Д.А., Головашина 0.В. Травмы культурной памяти: концептуальный анализ и методологические основания исследования // Вестник Томского государственного университета, 2017. - № 425. - С. 78-84.

6. Ассман Я. Культурная память: Письмо, память о прошлом и политическая идентичность в высоких культурах древности // Москва: Языки славянской культуры, 2004. - 368 с.

7. Ассман А. Длинная тень прошлого: Мемориальная культура и историческая политика // Москва: Новое литературное обозрение, 2014 . - 328 c.

8. Вельцер Х. История, память и современность прошлого // Неприкосновенный запас, 2005. - № 2. - [Электронный ресурс] - Режим доступа: httрs:// magazines.gorky.media/nz/2005/2/istoriya-pamyat-i-sovremennost-proshlogo.html.

9. Завадский А. Нам нужна своя Ассман // Исследования социальной политики, 2015. - № 3. - С. 501-508.

10. Князева Е.Н., Кюрдюмов С.П. Законы эволюции и самоорганизации сложных систем // Москва: Наука, 1994. - 236 с.

11. Леви-Строс К. Первобытное мышление // Москва: ТЕРРА - Книжный клуб; Республика, 1999. - 392 с.

12. Малимонов И.В., Король Л.Г., Синьковская И.Г., Рахинский Д.В. Проблема брачного поведения студенческой молодежи // Современные исследования социальных проблем, 2015. - № 10. - С. 202-219.

13. Малимонов И.В., Синьковская И.С., Король Л.Г., Рахинский Д.В. Современные семейные ценности в контексте макросоциальных изменений // Вестник ВятГГУ, 2016. - № 5. - С. 24-27.

14. Мельник Л.Г. Фундаментальные основы развития // Суммы: ИТД: «Университетская книга», 2003. - 288 с.

15. Миклина Л.И. Социальная память современной российской молодежи // Власть, 2015. - № 1. - С. 136-140.

16. Нора П. Всемирное торжество памяти // Неприкосновенный запас, 2005. - № 2-3. (40-41). - [Электронный ресурс] - Режим доступа: http://magazines. russ.ru/nz/2005/2/nora22.html.

17. Покида А.Н., Забуновская Н.В. Динамика исторической памяти в российском обществе (по результатам социологического мониторинга) // Социологические исследования, 2016. - № 3. - С. 98-107.

18. Репина Л.П. События и образы прошлого в исторической и культурной памяти // Новое прошлое, 2016. - № 1. - С. 82 -99.

19. Руденко А.П. Самоорганизация и синергетика. - [Электронный ресурс] - Режим доступа: http://spkurdyumov.ru/what/samoorganizaciya-i-sinergetika-a-prudenko/.

20. Хальбвакс М. Социальные рамки памяти // Москва: Новое издательство, 2007. - 348 с.

21. Malimonov, I.V., Rakhinsky D.V., Sinkovskaya I.G., Korol L.G., Aisner L.Yu., Bershadskaya S.V., Trashkova S.M. Global changes of family unit in modern Russia // Astra Salvensis, 2018. - V. 6. - № 12. - P. 623-634.

( ) Лунев Владимир Викторович (vladimirL1@yandex.ru), Мусат Раиса Павловна (lozraisa@yandex.ru), Лунева Tатьяна Анатольевна (luneva@sibsau.ru), Князев Николай Алексеевич (knyazev@sibsau.ru), Нескрябина Ольга Федоровна (nescr@mail.ru), Рахинский Дмитрий Владимирович (siridar@mail.ru). 